\title{
COMPARISON OF ALVARADO SCORE AND RIPASA SCORE IN THE ACCURATE DIAGNOSIS OF ACUTE APPENDICITIS IN COMBINED MILITARY HOSPITAL RAWALPINDI
}

\author{
Muhammad Majid, Rasikh Maqsood, Muhmmad Ali, Muhammad Ayub Ashraf Malhi, Zaki Hussain*, Muhammad Hanif Abbasi* \\ Combined Military Hospital/National University of Medical Sciences (NUMS) Rawalpindi Pakistan, *Pak Emirates Military Hospital/National University of \\ Medical Sciences (NUMS) Rawalpindi Pakistan
}

\section{ABSTRACT}

Objective: To determine the diagnostic accuracy of Alvarado score and the RIPASA score for acute appendicitis using histopathology as a gold standard.

Study Design: Cross sectional validation study.

Place and Duration of Study: Department of General Surgery, Combined Military Hospital, Rawalpindi Pakistan, from Mar to Sep 2018.

Methodology: A total number of 270 patients were included in the study presenting with pain right iliac fossa to the Accident and Emergency department. Surgeons and Seniors Residents in Surgery on call in the Accident and Emergency Department. Combined Military Hospital, Rawalpindi, scored the patients with suspicion of acute appendicitis with Alvarado Score and RIPASA score simultaneously. After appendectomy of these patients, the removed appendix was sent for histopathology to confirm whether it was normal or inflamed. A $2 \times 2$ table was used for calculating sensitivity, specificity and diagnostic accuracy of the RIPASA score and Alvarado Score. The two scoring systems were then compared for diagnostic accuracy.

Results: In our study, the sensitivity, specificity, positive predictive value, negative predictive value and diagnostic accuracy of RIPASA score and Alvarado score for diagnosing acute appendicitis were $92.1 \%, 62.1 \%, 95.2 \%, 48.6 \%, 88.9 \%$ and $72.6 \%$, $68.9 \%, 95.1 \%, 23.2 \%, 72.2 \%$ respectively.

Conclusion: The diagnostic accuracy of RIPASA score was more than that of Alvarado score in diagnosing acute appendicitis.

Keywords: Acute appendicitis, Alvarado score, RIPASA score.

How to Cite This Article: Majid M, Maqsood R, Ali M, Malhi MAA, Hussain Z, Abbasi MH. Comparison of Alvarado Score and RIPASA Score in the Accurate Diagnosis of Acute Appendicitis in Combined Military Hospital Rawalpindi. Pak Armed Forces Med J 2021; 71(5): 1519-1523. doi: https://doi.org/10.51253/pafmj.v71i5.3596

This is an Open Access article distributed under the terms of the Creative Commons Attribution License (https://creativecommons.org/licenses/by-nc/4.0/), which permits unrestricted use, distribution, and reproduction in any medium, provided the original work is properly cited.

\section{INTRODUCTION}

Acute appendicitis was first described by Fitz et al in 1886 in a study titled as 'perforating inflammation of the vermiform appendix'. ${ }^{1}$ McBurney et al further worked on acute appendicitis elaborating its signs and symptoms. ${ }^{1}$ He described the point of maximum tenderness in the right iliac fossa which bears his name. The McBurney point is a guide while examining such a patient and then giving the surgical incision subsequently.

The diagnosis of acute appendicitis is based on a thorough clinical judgment including a detailed history and clinical examination. The aetiology of acute appendicitis is thought to be multifactorial in which luminal obstruction, dietary and familial factors have all been documented ${ }^{1}$. Many trials have been conducted to assess the role of conservative treatment for acute appendicitis. However, classically the treatment of choice is an emergency appendectomy.

Correspondence: Dr Muhammad Majid, Department of Surgery, Combined Military Hospital Kohat Pakistan

Received: 06 Dec 2019; revision received: 01 Oct 2020; accepted: 06 Oct 2020
Acute appendicitis is one of the most common surgical emergencies presented to the Accident and Emergency Departments in which the surgeon has to take a quick decision about its operative management ${ }^{1}$. The lifetime prevalence of acute appendicitis is about $22 \%$ ranging between $13-77 \% .^{2}$

Different clinical scoring systems have been made for the diagnosis of acute appendicitis in which Alvarado Score is widely used.3,4 Recently RIPASA scoring system has been developed in 2010 preferably for Asian population. ${ }^{5}$ It is more elaborated in terms of patient demographic factors and clinical components as compared to the already existing Alvarado Score. ${ }^{6}$

Although acute appendicitis is a common surgical problem, still a negative appendectomy rate of $20-40 \%$ exists in many parts of the world, which is associated with a definitive morbidity. ${ }^{7}$ The negative appendectomy rate reported in a study conducted in Pakistan Institute of Medical Sciences Islamabad, Pakistan was $17.5 \%^{8}$. A more accurate scoring system for the clinical diagnosis of acute appendicitis needs to be adopted to reduce these unnecessary appendectomies. 
In 1986, Alvarado developed a clinical scoring system for the diagnosis of acute appendicitis known as Alvarado Score. ${ }^{4}$ The score has 6 clinical items and 2 laboratory measurements with a total of 10 points (Table-I).

An Alvarado score of 7 or more is considered as probable acute appendicitis and $<7$ is considered as less probable. Imaging studies like ultrasound and computed tomography usually aid in the diagnosis of acute appendicitis. However, in circumstances where the imaging is not available the diagnostic scoring systems can be very useful in deciding the management of such patients ${ }^{4}$.

The RIPASA score is a recently developed clinical scoring system applied in the diagnosis of acute appendicitis. ${ }^{5}$ It was developed in 2010 and was advocated for use in Asian population with a better sensitivity and specificity as compared to Alvarado score. The score has 2 patient demographic components, 10 clinical items and 2 laboratory measurements with a total of 16.5 points as shown in Table-II.

A RIPASA score of 7.5 or more is considered as probable acute appendicitis and $<7.5$ is considered as less probable. ${ }^{5}$

Most of the hospital settings around the world follow the Alvarado scoring system for the diagnosis of acute appendicitis as mentioned earlier. ${ }^{4}$ Likewise our hospital settings also use the Alvarado scoring system. But literature review of the comparison of the newly developed RIPASA score and Alvarado score for the diagnosis of acute appendicitis shows the superiority of the new RIPASA scoring system in diagnosis over the Alvarado scoring system. ${ }^{6,8-10}$ But the studies comparing these two scoring systems has not been done on local population of Pakistan except Karachi. ${ }^{10}$

The above critique signifies the importance of more such studies that need to be conducted in this regard in our clinical settings so as to adopt a better diagnostic scoring system for acute appendicitis. It would greatly help our surgeons to take a better decision regarding operative management of such patients with more confidence to avoid missed diagnosis of acute appendicitis which can lead to deleterious complications like perforation of the acutely inflamed appendix. ${ }^{9}$ Likewise it would also help the patients by decreasing the unnecessary appendectomies performed on them thereby decreasing the morbidity associated with these operative procedures. ${ }^{11}$ By reducing the morbidity of the patients associated with unnecessary appendectomies, the unnecessary logistic costs would also be reduced. Unwanted admissions and expensive imaging studies can also be avoided by adopting a better scoring system.

\begin{tabular}{|c|c|c|}
\hline \multicolumn{3}{|l|}{ Alvarado Score } \\
\hline \multicolumn{3}{|l|}{ Symptoms } \\
\hline \multicolumn{2}{|c|}{ Abdominal pain that migrates to the right iliac fossa } & 1 \\
\hline \multicolumn{2}{|c|}{ Anorexia (loss of appetite) } & 1 \\
\hline \multicolumn{2}{|l|}{ Nausea or vomiting } & 1 \\
\hline \multicolumn{3}{|l|}{ Signs } \\
\hline \multicolumn{2}{|l|}{ Tenderness in the right iliac fossa } & 2 \\
\hline \multicolumn{2}{|l|}{ Rebound tenderness } & 1 \\
\hline \multicolumn{2}{|l|}{ Fever of $37.3^{\circ} \mathrm{C}$ or more } & 1 \\
\hline \multicolumn{3}{|l|}{ Laboratory } \\
\hline \multicolumn{2}{|l|}{ Leukocytosis $>10,000$} & 2 \\
\hline \multicolumn{2}{|l|}{ Neutrophilia $>70 \%$} & 1 \\
\hline \multicolumn{2}{|l|}{ Total } & 10 \\
\hline \multicolumn{3}{|l|}{ Table-II: RIPASA Score (5). } \\
\hline \multicolumn{3}{|l|}{$\begin{array}{l}\text { RIPASA Score } \\
\end{array}$} \\
\hline Patient Characteristics & Score & \\
\hline \multicolumn{3}{|l|}{ Gender } \\
\hline Female & \multicolumn{2}{|l|}{0.5} \\
\hline Male & \multicolumn{2}{|l|}{1.0} \\
\hline \multicolumn{3}{|l|}{ Age } \\
\hline$<40$ years & \multicolumn{2}{|l|}{1.0} \\
\hline$>40$ years & \multicolumn{2}{|l|}{0.5} \\
\hline \multicolumn{3}{|l|}{ Symptoms } \\
\hline Right iliac fossa (RIF) pain & \multicolumn{2}{|l|}{0.5} \\
\hline Pain migration to RIF & \multicolumn{2}{|l|}{0.5} \\
\hline Anorexia & \multicolumn{2}{|l|}{1.0} \\
\hline Nausea and Vomiting & \multicolumn{2}{|l|}{1.0} \\
\hline \multicolumn{3}{|l|}{ Duration of Symptoms } \\
\hline$<48 \mathrm{~h}$ & 1.0 & \\
\hline$>48 \mathrm{~h}$ & 0.5 & \\
\hline Signs & & \\
\hline RIF tenderness & 1.0 & \\
\hline Guarding & 2.0 & \\
\hline Rebound tenderness & 1.0 & \\
\hline Rovsing's Sign & 2.0 & \\
\hline Fever $>37 \mathrm{C},<39 \mathrm{C}$ & 1.0 & \\
\hline Investigations & & \\
\hline Raised White cell count & 1.0 & \\
\hline Negative urinalysis & 1.0 & \\
\hline Total & 16.5 & \\
\hline
\end{tabular}

The study conducted is of help to the junior doctors, surgical trainees and young surgeons because this group of doctors usually comes across such cases during their duties in the Accident and Emergency departments (A \& E) of a hospital. RIPASA score is a bit lengthy one but if properly displayed in the A \& E then it can be easily followed. It is also stressed that USG abdomen may also be done especially in female patients if the facility is available. It will help in excluding other causes of pain in right iliac fossa. ${ }^{2}$ The 
objective of study was to determine diagnostic accuracy of Alvarado score and the RIPASA score for acute appendicitis using histopathology as a gold standard.

\section{METHODOLOGY}

This cross sectional validation study conducted in General Surgery Department, Combined Military Hospital (CMH) Rawalpindi, from March to September 2018. Permission was taken from institutional review board and ethical committee (Certificate No. 10/04/19) for conducting this study.

The sample size of this study was taken as 270 according to WHO calculator based upon the justification given; the expected sensitivity and specificity of RIPASA Score: $98 \%$ and $81 \%$ (6), the expected sensitivity and specificity of Alvarado score: $68 \%$ and $88 \%$ (6), the prevalence of acute appendicitis: $22 \%$ (2), desired precision: $0.05(5 \%)$, confidence level: $95 \%$.

The sample size for measuring sensitivity and specificity for RIPASA score taking into account the above prevalence, desired precision and confidence level was 270 and that for Alvarado score was 120 . Therefore, for comparison of these two scores, the sample size used was 270. The sampling technique adopted was non-pro-bability, consecutive sampling.

Inclusion Criteria: The patients included were adults ranging from 12-80 years of both the genders presenting with pain right iliac fossa to the A\&E Department.

Exclusion Criteria: The patients excluded were all patients presenting with non-RIF pain, those who have previously undergone appendectomy and those referred with known cause of abdominal pain, patients with generalized peritonitis, pregnant females, patients with any abdominal or pelvic malignancy and patients with appendicular abscess.

Surgeons and seniors residents in surgery on call in the A \& E Dept CMH, Rawalpindi scored the patients with suspicion of acute appendicitis with Alvarado Score and RIPASA score simultaneously. For convenience, boards and charts were displayed in the A \& E Dept clearly depicting Alvarado and RIPASA score. Those senior residents finding any difficulty in the new RIPASA score were educated by the classified surgeons. The temperature measurement and blood complete picture samples were taken at the same time for both the Alvarado Score and RIPASA score. Informed consent was taken for inclusion into the study when the patients were pain free. After the appendectomy of these patients, the removed appendix was sent for histopathology to confirm whether it was normal or inflamed.

Data were entered and analyzed using SPSS-16 version. Age distribution of the patients was calculated along with the mean patient age. Gender distribution was also calculated. A $2 \times 2$ table was used for calculating sensitivity, specificity and diagnostic accuracy of the RIPASA score and Alvarado Score (Table-III).

Table-III: Diagnostic score comparison.

\begin{tabular}{l|c|c}
\hline $\begin{array}{l}\text { Diagnostic Score } \\
\text { (Either RIPASA } \\
\text { or Alvarado) }\end{array}$ & \multicolumn{2}{|c}{ Histopathology of Appendix } \\
\cline { 2 - 3 } & $\begin{array}{c}\text { Inflamed } \\
\text { Appendix }\end{array}$ & $\begin{array}{c}\text { Normal } \\
\text { Appendix }\end{array}$ \\
\hline$\geq 7.5$ & True Positive (a) & False Positive (b) \\
\hline$<7.5$ & False Negative (c) & True Negative (d) \\
\hline
\end{tabular}

The diagnostic accuracy of the two scoring systems was calculated and compared.

\section{RESULTS}

The demographic characteristics of the 270 patients included in the study were calculated. The number of male patients included in the study were $162(59.9 \%)$ and female patients were $108(40.1 \%)$. The mean age of the patients was $26.6 \pm 9.26$. Almost $83 \%$ of the patients were below the age of 40 years while only $3 \%$ were above 60 years.

Out of 270 patients who underwent appendectomy, 241 had an inflamed appendix on histopathology and 29 patients on histopathology had normal appendix. The negative appendectomy rate was $10.7 \%$. The sensitivity, specificity, positive predictive value, negative predictive value of RIPASA score and Alvarado score were calculated by $2 \times 2$ table as shown in Table-IV.

Table-IV: Table for RIPASA and Alvarado Score.

\begin{tabular}{l|c|c}
\hline \multirow{2}{*}{$\begin{array}{l}\text { RIPASA } \\
\text { Score }\end{array}$} & \multicolumn{2}{|c}{ Histopathology of Appendix } \\
\cline { 2 - 3 } & $\begin{array}{c}\text { Inflamed } \\
\text { Appendix }\end{array}$ & $\begin{array}{c}\text { Normal } \\
\text { Appendix }\end{array}$ \\
\hline$\geq 7.5$ & $222(82 \%)$ & $11(4 \%)$ \\
\hline$<7.5$ & $19(7 \%)$ & $18(6 \%)$ \\
\hline Alvarado Score & \multicolumn{2}{|l}{} \\
\hline$\geq 7$ & $175(64 \%)$ & $9(3 \%)$ \\
\hline$<7$ & $66(24 \%)$ & $20(7 \%)$ \\
\hline
\end{tabular}

Sensitivity for RIPASA score $=222 / 222 \pm 19 \times 100$ $=92.1 \%$, specificity for RIPASA score $=18 / 11 \pm 18 \times 100$ $=62.1 \%$, positive predictive value for RIPASA score $=$ $222 / 222 \pm 11 \times 100=95.2 \%$, negative predictive value for RIPASA score $=18 / 19 \pm 18 \times 100=48.6 \%$, diagnostic accuracy for RIPASA score $=222 \pm 18 / 222 \pm 11 \pm 19 \pm$ $18 \times 100=88.9 \%$. 
Sensitivity for Alvarado score $=175 / 175 \pm 66 \times 100$ $=72.6 \%$, specificity for Alvarado score $=20 / 9 \pm 20 \times 100$ $=68.9 \%$, positive predictive value for Alvarado score $=$ $175 / 175 \pm 9 \times 100=95.1 \%$, negative predictive value for Alvarado score $=20 / 66 \pm 20 \times 100=23.2 \%$, diagnostic accuracy for Alvarado score $=175 \pm 20 / 175 \pm 9 \pm 66 \pm$ $20 \times 100=72.2 \%($ Table-V).

Table-V: Comparison of RIPASA Score/Alvarado Score.

\begin{tabular}{l|c|c}
\hline & RIPASA Score \% & Alvarado Score \% \\
\hline Sensitivity & 92.1 & 72.6 \\
\hline Specificity & 62.1 & 68.9 \\
\hline $\begin{array}{l}\text { Diagnostic } \\
\text { Accuracy }\end{array}$ & 88.9 & 72.2 \\
\hline
\end{tabular}

\section{DISCUSSION}

Acute appendicitis is a common surgical emergency at least in the young adults. ${ }^{12,13}$ The diagnosis depends upon a thorough clinical acumen of the doctor in the accident and emergency department. Laboratory investigations and imaging like ultrasound abdomen may augment the clinical assessment but the prime role is played by a careful clinical examination of the abdomen. The sensitivity and specificity of the computed tomography scan of the abdomen and pelvis for diagnosing acute appendicitis is high. However, it cannot be used in every patient as it is not widely available in most of our settings. Also in tertiary care setups due to an increase demand on radiologists, accurate reporting of such a scan cannot be done usually in emergency settings.

The challenge in the management of acute appendicitis is not just that of a clinical diagnosis but also of an early surgical intervention. If there is an ambiguity in the clinical diagnosis then an early intervention may warrant a negative appendectomy. To avoid such an unfortunate situation, different scoring systems have been used by the surgeons for the diagnosis of acute appendicitis. Alvarado score, ${ }^{14,15}$ has historically been used for scoring in the diagnosis of acute appendicitis. It is still taught in medical colleges throughout the world and so it is the widely used scoring system. Other scoring systems include Tzanaki, Eskelinen, Lindberg and appendicitis inflammatory response score. ${ }^{16,17}$

RIPASA score has been recently developed in the last decade for the Asian population. Age, gender and duration of symptoms have also been taken into account in RIPASA score. Various studies have been done to compare the usefulness of Alvarado score and the RIPASA score in the diagnosis of acute appendicitis.
They have regarded RIPASA score as superior to Alvarado score in terms of diagnostic accuracy.

In our study the sensitivity, specificity, positive predictive value, negative predictive value and diagnostic accuracy of RIPASA score and Alvarado score for diagnosing acute appendicitis is $92.1 \%, 62.1 \%$, $95.2 \%, 48.6 \%, 88.9 \%$ and $72.6 \%, 68.9 \%, 95.1 \%, 23.2 \%$, $72.2 \%$ respectively.

A study conducted in CMH Kohat in 2012 evaluated the usefulness of RIPASA score as a new diagnostic score for acute appendicitis for the local population with a diagnostic accuracy of $95.1 \% .{ }^{9}$ In the same study the sensitivity of RIPASA score was $96.7 \%$, specificity was $93 \%$, positive predictive value was $94.8 \%$ and negative predictive value was $95.54 \% .{ }^{9}$ There is a single study conducted in Pakistan on the population of Karachi in 2015 which has concluded that RIPASA is a reliable and sensitive diagnostic tool in comparison to Alvarado score to diagnose acute appendicitis. ${ }^{10}$ According to this study, sensitivity of RIPASA score for diagnosing acute appendicitis was $91.11 \%$, specificity was $60 \%$, positive predictive value (PPV) was $95.34 \%$, negative predictive value (NPV) was $42.85 \%$ and diagnostic accuracy was $88 \%$. Sensitivity of Alvarado score was $11.67 \%$, specificity was $95 \%$, PPV was $95.45 \%$, and NPV was $10.67 \%$ and diagnostic accuracy was $20 \% .{ }^{10}$

A study conducted in Rajasthan India showed the sensitivity, specificity, positive predictive value, negative predictive value and diagnostic accuracy of RIPASA score and Alvarado score for diagnosing acute appendicitis as $94.7 \%, 60 \%, 97.8 \%, 37.5 \%, 93 \%$ and $67.3 \%, 80 \%, 98.4 \%, 11.4 \%, 68 \%$ respectively. ${ }^{18}$ Another study conducted in Jordan revealed that the sensitivity, specificity, positive predictive value, negative predictive value and diagnostic accuracy of RIPASA score and Alvarado score for diagnosing acute appendicitis is $93.2 \%, 61.8 \%, 92.2 \%, 64.9 \%, 91.5 \%$ and $73.7 \%, 68.6 \%$, $92.1 \%, 34.8 \%, 74.3 \% .{ }^{19}$

The results of our study were in coherence with international studies. RIPASA score has sensitivity and diagnostic accuracy more than that of Alvarado score. The reason may be the addition of gender, age and duration of symptoms which affect the diagnosis. It also has the inclusion of roving's sign and guarding which may play a more diagnostic role in picking up the localized peritonism due to acute appendicitis. The addition of a negative urine analysis also helps to differentiate the urinary tract causes of pain in right iliac fossa from acute appendicitis. However, it may be 
noted that Alvarado score has more specificity as compared to RIPASA score and it has been documented in other international studies as well.

\section{CONCLUSION}

The diagnostic accuracy of RIPASA score was $89 \%$ which was more than that of Alvarado score (72\%) in diagnosing acute appendicitis. Its use may be encouraged in our settings as compared to Alvarado score in order to pick up the diagnosis that would otherwise be missed by Alvarado score. It may also reduce the negative appendectomy rates in our settings by accurately diagnosing acute appendicitis.

\section{Conflict of Interest: None.}

\section{Authors' Contribution}

MM: Data collection \& analysis, RM: Study design \& intellectual support, MA: Collection of data, MAAM: Data analysis, ZH: Discussion of data, MHA: Data analysis.

\section{REFERENCES}

1. Makama JG. Is acute appendicitis still the most common abdominal surgical emergency. Arch Med Surg 2017; 2(1): 1-2.

2. Pedram A, Asadian F, Roshan N. Diagnostic accuracy of abdominal ultrasonography in ediatric acute appendicitis. Bull Emerg Trauma 2019; 7(3): 278-283.

3. Xingye W, Yuqiang L, Rong W, Hongyu Z. Evaluation of diagnostic scores for acute appendicitis. J College Physician Surgeon Pakistan 2018; 28(2): 110-114.

4. Alvarado A. Improved alvarado score (Mantrels) for the early diagnosis of acute appendicitis. Int J Surg Res Pract 2019; 6(1): 1-6.

5. Chong CF, Thien A, Mackie AJ, Tin AS, Tripathi S, Ahmad MA. Evaluation of the RIPASA score: A new scoring system for the diagnosis of acute appendicitis. Sing Med J 2010; 51(3): 220-225.

6. Chong CF, Thien A, Mackie AJ, Tin AS, Tripathi S. Comparison of RIPASA and Alvarado scores for the diagnosis of acute appendicitis. Singapore Med J 2011; 52(5): 340-345.

7. Chumpon W, Thunyarat A, Napaphat P, Mark M, John A. Diagnostic scores for appendicitis: A systemic review of scores performance. British J Med Med Res 2014; 4(2): 711-730.
8. Nanjundiah N, Mohammed A, Shanbhag V, Ashfaque K, Priya SA. A comparative study of RIPASA Score and ALVARADO Score in the diagnosis of acute appendicitis. J Clin Diag Res 2014; $8(11): 3-5$.

9. Butt MQ, Chatha SS, Ghumman AQ. RIPASA score: A new diagnostic score for diagnosis of acute appendicitis. J Coll Physicians Surgeon Pak 2014; 24(12): 894-897.

10. Damani SAAR, Shah SSH, Hashami A, Mansoori MS. Effective diagnosis of acute appendicitis - comparison of RIPASA and alvarado scoring systems. J Coll Physician Surgeon Pakistan 2016; 21(3): 88-91.

11. Lu Y, Freidlander S, Lee SL. Negative appendectomy: clinical and economic implications. Am Surg 2016; 82(10): 1018-1022.

12. Snyder MJ, Guthrie M, Cagle S. Acute appendicitis: efficient diagnosis and management. Am Fam Phy 2018; 98(1): 25-33.

13. Ceresoli M, Zucchi A, Allievi N, Harbi A, Pisano M, Montori G, et al. Acute appendicitis: epidemiology, treatment and outcomesanalysis of 16544 consecutive cases. World J Gastrointest Surg 2016; 8(10): 693-699.

14. Ozsoy Z, Yenidogan E. Evaluation of the Alvarado scoring system in the management of acute appendicitis. Turk J Surg 2017; 33(3): 200-204.

15. Apisarnthanarak $P$, Suvannarerg V, Pattaranutaporn $P$, Charoensak A, Raman SS, Apisarnthanarak A. Alvarado score: can it reduce unnecessary CT scans for evaluation of acute appendicitis. Am J Emerg Med 2015; 33(1): 266-70.

16. Shuaib A, Shuaib A, Fakhra Z, Marafi B, Alsharaf K, Behbehani A. Evaluation of modified Alvarado scoring system and RIPASA scoring system as diagnostic tools of acute appendicitis. World J Emerg Med 2017; 8(4): 276-280.

17. Siddique K, Baruah P, Bhandari S, Mirza S, Harinath G. Diagnostic accuracy of white cell count and C-reactive protein for assessing the severity of paediatric appendicitis. JRSM Short Rep 2011; 2(7): 59-65.

18. Regar MK, Choudhary GS, Nogia C, Pipal DK, Agrawal A, Srivastava $\mathrm{H}$. Comparison of Alvarado and RIPASA scoring systems in diagnosis of acute appendicitis and correlation with intraoperative and histopathological findings. Int Surg J 2017; 4(5): 1755-1761.

19. Alnjadat I, Abdallah B. Alvarado versus RIPASA score in diagnosing acute appendicitis. Rawal Med J 2013; 38(2): 147-151. 